\title{
Assessment of male sterility and antioxidant enzyme activities induced by the chemical hybridization agent SQ-1 in foxtail millet (Setaria italica)
}

\author{
Haiying Zhang, Pingyi Guo*, Yuguo Wang, Xiangyang Yuan, Shuqi Dong, Xi'e Song, Jixiang Wang, \\ Yinyuan Wen \\ Laboratory of Crop Chemical Regulation and Chemical Weed Control, College of Agriculture, Shanxi Agricultural University, Taigu, 030800, \\ People's Republic of China
}

\section{A B S TR A C T}

\begin{abstract}
Male sterility induced by chemical hybridization agents (CHAs) is a highly potential approach for heterosis in crop breeding. To investigate the effects of male sterility induced by SQ-1 in foxtail millet (Setaria italica), experiments were conducted with various SO-1 concentrations and at different plant developmental stages of the foxtail millet Henggu 13 in 2015 and 2016. Some studies have suggested that CHA induced male sterility may suffer from oxidative stress. To study the physiological responses, the production and scavenging effects of the reactive oxygen species (ROS) were investigated. The results showed that the maximum male sterility was obtained at the early protogyny stage when a SQ-1 concentration of $5 \mathrm{~kg} \mathrm{ha}^{-1}$ was applied. The spikelets of the SQ-1 treated plants presented higher contents of $\mathrm{H}_{2} \mathrm{O}_{2}$ and MDA than those of untreated plants at all stages of the treatment. Moreover, the activities of superoxide dismutase (SOD), catalase (CAT), and ascorbate peroxidase (APX) in scavenging ROS in the spikelets were down regulated at different SQ-1 concentrations when compared to the ones determined for the control plants. However, the SQ-1 treated spikelets presented a higher peroxidase (POD) concentration than the control plants, but the quantity was not enough to eliminate the produced ROS. In addition, the proline and soluble protein contents were both lower than the one of the control plants. In conclusion, the sterility could be induced by SQ-1 due to the chronic oxidative stress caused by the abnormal increase of ROS.
\end{abstract}

Keywords: Chemical hybridizing agents (CHA); Foxtail millet; Male sterility; Physiological responses; SQ-1

\section{INTRODUCTION}

Foxtail millet (Setaria italica) is largely cultivated globally and belongs to one of the most ancient crop species that was probably domesticated in China from the wild species green foxtail nearly 11500 years ago (Lu et al., 2009; Yang et al., 2012). Due to its excellent drought resistance and water management, it is produced for staple food in the arid and semiarid zones of mainly China and India before the popularity of rice and wheat arose (Bettinger et al., 2010; Zohary et al., 2012; Crawford, 2006). It presents the advantage to be nutritionally superior to other cereals such as wheat and rice (Saleh et al., 2013; Upadhyaya et al., 2011) because it is rich in proteins, minerals, vitamins, and phytochemicals, and contains eight essential amino-acids except lysine (Matz, 1991). In recent years, foxtail millet became an ideal model crop for genomics studies and abiotic challenges because of its small diploid genome ( $510 \mathrm{Mb})$ (Jia et al., 2013; Doust et al., 2009; Brutnell et al., 2010; Li and Brutnell, 2011; Lata et al., 2013).

Heterotic vigors obtained from the expression by cross fertilization of genetically different parental lines, showed superior phenotypes to their parents, such as high yield production, increased growth and development rates, improved biomass, better quality, improved stress resistance among others (Hei et al., 2016; Kalloo et al., 2006). Moreover, the strong inbreeding character and floral architecture of foxtail millet hinder seeds explosions, leading to a reduced number of applicable hybrids. Many approaches have been developed to avoid self-fertilization in the case of hybrid seeds production in many cereal crops, such as emasculation, genetic male sterility (GMS), cytoplasmic male sterility (CMS), and photo-thermo-

\footnotetext{
${ }^{*}$ Corresponding author:

Pingyi Guo, Laboratory of Crop Chemical Regulation and Chemical Weed Control, College of Agriculture, Shanxi Agricultural University, Taigu, 030800, People's Republic of China. E-mail: pyguo126@126.com
} 
sensitive male sterility (Chen et al., 2010). However, the cited explored hybrid systems present important inconveniences. (Ikeguchi et al., 1999; Singh et al., 2015). On the other hand, the discovery of chemical hybridizing agents (CHAs) is considered to be a promising method for the development of hybrid seeds. It is indeed flexible, rapid, and does not require fertility restoration (Ba et al., 2014b). In addition, the biggest advantage of applying CHAs is the broadening in the choice of combinations increasing the number of hybrid seeds that can be produced.

The best results have been reported with the use of the new type CHA SQ-1 in wheat, leading to an almost complete sterility at the concentration of $5 \mathrm{~kg} \mathrm{ha}^{-1}$. Indeed, when applied at a specific developmental stage, the pharmacodynamic tests in field experiments indicated that the out-crossing rate could reach up to $85 \%$. Besides, this CHA exhibited to be effective on a broad spectrum property and has no side effects on agronomic traits (Ba et al., 2013, 2014a; Zhu et al., 2012, 2013). Because of these advantages, SQ-1 replaced other CHAs and has been largely used to produce hybrid seeds in China. However, little information is known on the effect of SQ-1 on foxtail millet although some experiences have been reported in the case of wheat, for which the results could be potentially transferred to foxtail millet.

The production of reactive oxygen species (ROS) is triggered when plants are exposed to environmental changes. Among the ROS, hydroxyl radicals (OH-), singlet oxygen $\left({ }^{1} \mathrm{O}_{2}\right)$, superoxide anion $\left(\mathrm{O}_{2}{ }^{-}\right)$, and hydrogen peroxide $\left(\mathrm{H}_{2} \mathrm{O}_{2}\right)$ (Asada, 1999), are inherent by-products of the cell's metabolism. However, excessive accumulation of these substances can damage lipids, photosynthetic pigments, nucleic acids and proteins (Smirnoff, 1993; Sun et al., 2002), and ultimately lead to cellular structural lesions (Apel and Hirt, 2004), growth perturbation, reduced fertility, and premature senescence (Krasensky and Jonak, 2012). Malondialdehyde (MDA), a secondary breakdown product of lipid peroxidation, is regarded as an indicator of lipid peroxidation and oxidative damage (Teisseire and Guy, 2000). The agent SQ-1 is an abiotic stress that may provoke a response from the plant. To circumvent these drawbacks, plants produced enzymatic and non-enzymatic antioxidants that can scavenge ROS. These enzymatic antioxidants that play a role in the plant's defense system include superoxide dismutase (SOD), peroxidase (POD), catalase (CAT), and ascorbate peroxidase (APX). It has been reported that the level of enzymatic antioxidants increased as a reply to mild or moderate stress, but their efficiency decreased under continuous stressful environment (Fan et al., 2009; Liu et al., 2011; Ge et al., 2014). Plants also produce a large number of osmotic compounds, such proline as the most common one, in order prevent oxidative damage (Girousse et al., 1996).
Taking into account the upmost importance of this staple food, there is little information on the male sterility induced by CHA. In this study, we investigated the effects on male sterility of SQ-1 at various concentrations and at different developmental stages in foxtail millet. We compared the morphological features between SQ-1 treated plants and control plants. Moreover, agronomic characteristics and physiological parameters were also determined to understand the male sterility mechanism, which is of crucial importance for the development of physiological male sterility.

\section{MATERIALS AND METHODS}

\section{Experimental site}

The experiment was carried out at the Shanxi Agricultural University Farming Station (112.32E, 37.23N at $782.6 \mathrm{~m}$ elevation, Shanxi province, China) during the two successive seasons of 2015 and 2016. The climate of this region is continental temperate. The soil contained $24.49 \mathrm{~g} \mathrm{~kg}^{-1}$ organic matter, $0.1543 \%$ total salt, $1.001 \mathrm{~g} \mathrm{~kg}^{-1}$ total nitrogen, $51.92 \mathrm{mg} \mathrm{kg}^{-1}$ available nitrogen, $24.13 \mathrm{mg} \mathrm{kg}^{-1}$ available phosphorus, $183.6 \mathrm{mg} \mathrm{kg}^{-1}$ readily available potassium, and the $\mathrm{pH}$ value was 7.85 .

\section{Plant materials and chemicals}

In this study, the early-mutation cultivar of Henggu 13 was used, which was purchased from the Institute of Rainfed agriculture from the Hebei Academy of Agriculture and Forestry (Hebei, China). The CHA SQ-1 was kindly provided by the Cotton Research Institute from the Shanxi Academy of agricultural Science (Shanxi, China).

\section{Experimental treatments}

The study was conducted in a completely randomized design (CRD) with three independent experiments performed as biological replicates for all experiments. Four dosages of SQ-1 (3, 4, 5, and $\left.6 \mathrm{~kg} \mathrm{ha}^{-1}\right)$ were applied to investigate the male sterilization at three stages, namely early booting, midbooting, and early protogyny. Plants were considered to be at the early booting stage when the index of the leaf age was 61.67; at the mid-booting stage when the index of the leaf age was 79.94; and at the early protogyny stage when the index of the leaf age was 92.39. The SQ-1 solutions were applied with a small hand sprayer and distilled water was sprayed for the control experiments. The leaves of the plants were sprayed until complete run-off and care was taken to prevent spray drift by screening the plants from different plots with polyethylene sheets. After treatment, all panicles were individually bagged with parchment selling bags to avoid crosspollination or other contaminations. Young panicles were collected from the control and experimental groups (at 5, 10, and $15 \mathrm{~d}$ after treatment) and used for physiological traits analysis. At grain maturity, the percentage of male sterility was assessed using the following equation: 
Percent of male sterility $(\%)=100 *(1-\mathrm{Nt} / \mathrm{Nc})$

Where $\mathrm{Nt}$ is the average number of grains observed on SQ-1 treated plants and

$\mathrm{Nc}$ is the average number of grains observed on 10 ears of the control plants.

Other parameters such as the plant height, panicle length, mean value of spikelets per ear, and the mean value of grains per spikelets, were also recorded.

\section{Phenotypic characterization}

Plant spikelets were photographed using a Canon digital camera (EOS 5D, Canon, Japan) mounted with a Canon Zoom Lens (EF 24-70 mm1:2.8, USM), and plant flowers were photographed using a Canon DP27 digital camera (Canon, Japan) mounted on an Olympus dissecting microscope (SZX16, Olympus, Japon).

Anthers of mature flowers were collected after each treatment at anthesis and then pollen grains were stained with $2 \%$ iodine-potassium iodide solution ( $\mathrm{I}_{2}-\mathrm{KI}$ ) followed by an examination under an Olympus light microscope (BX53, Olympus, Japon) to analyze the pollen fertility.

\section{Determination of lipid peroxidation and hydrogen peroxide $\left(\mathrm{H}_{2} \mathrm{O}_{2}\right)$ concentrations}

The $\mathrm{H}_{2} \mathrm{O}_{2}$ concentration was determined by slightly modifying the method described by Patterson et al. (1984). Briefly, a fresh spikelets sample (0.3 g) was grinded in an ice bath with ice cold acetone $(3 \mathrm{~mL})$ and then centrifuged at $3000 \times \mathrm{g}$ for $10 \mathrm{~min}$. Then, the supernatant $(1 \mathrm{~mL})$ was added to a mixture containing titanium disulfate $\left(\mathrm{Ti}\left(\mathrm{SO}_{4}\right)_{2},(5 \% \mathrm{w} / \mathrm{v}\right.$ in water, $0.1 \mathrm{~mL})$ and ammonia (12 M, $0.2 \mathrm{~mL})$. The obtained precipitate was washed three to five times with ice cold acetone and resuspended in sulfuric acid $\left(\mathrm{H}_{2} \mathrm{SO}_{4}, 2 \mathrm{M}, 5 \mathrm{~mL}\right)$. The absorbance of the sample was read at $410 \mathrm{~nm}$ on a spectrophotometer (UV1200, MAPADA, China), and the concentration of $\mathrm{H}_{2} \mathrm{O}_{2}$ was calculated based on a standard curve.

The oxidative damage of spikelets lipids was measured by determining the concentration of malondiadehyde (MDA). The concentration of MDA was determined by chemical reaction with thiobarbituric acid (TBA) following the method of Cakmak and Horst (1991) with some modifications. A sample of fresh spikelets $(0.1 \mathrm{~g})$ was ground in trichloroacetic (TCA, $0.1 \% \mathrm{w} / \mathrm{v}$ in water, $5 \mathrm{~mL}$ ) and centrifuged at $12000 \times \mathrm{g}$ for $10 \mathrm{~min}$ in a refrigerated centrifuge. An aliquot of $1 \mathrm{~mL}$ of a solution of extracted enzyme was added to a solution of TBA $(0.5 \% \mathrm{w} / \mathrm{v}$ in $20 \% \mathrm{w} / \mathrm{v}$ TCA in water, $4 \mathrm{~mL}$ ). The solution was incubated at $100^{\circ} \mathrm{C}$ for $15 \mathrm{~min}$. Thereafter, the reaction was stopped by transferring the tubes into an ice bath. The samples were then centrifuged at $12000 \times \mathrm{g}$ for $5 \mathrm{~min}$ and the absorbance was read at 532 and $600 \mathrm{~nm}$ with a spectrophotometer (UV1200, MAPADA, China). The MDA concentration was calculated using the following equation:

MDA $(m m o l g F W)=\left[\left(A_{532 \mathrm{~nm}}-A_{600 \mathrm{~nm}}\right) \times \mathrm{V} / \varepsilon\right] \times W$

Where, $\varepsilon$ refers to the extinction coefficient $(155 \mathrm{mM} \mathrm{cm})$.

Extraction and determination of the activities of the antioxidant enzymes

For the extraction of antioxidant enzymes, a sample of fresh spikelets $(0.1 \mathrm{~g})$ was homogenized in phosphate buffer $(50 \mathrm{mM}, \mathrm{pH} 7.8$, containing $1 \mathrm{mM}$ of EDTA, $0.05 \% \mathrm{w} / \mathrm{v}$ Triton X-100 and $1 \% \mathrm{w} / \mathrm{v}$ polyvinypyrrolidone, $1.5 \mathrm{~mL}$ ) followed by homogenization and centrifugation at $12000 \times \mathrm{g}$ for $20 \mathrm{~min}$ at $4^{\circ} \mathrm{C}$. The supernatant was taken for the enzymatic assays of SOD, POD, CAT, and APX. For the determination of the APX activity, additional ascorbate $(1.0 \mathrm{mM})$ was added to the buffer mentioned above. The total soluble protein concentrations of the enzyme extracts were determined by Bradford assay (1976) using bovine serum albumin as a standard.

The SOD activity was determined based on the inhibition of the photoreduction of nitro-blue tetrazolium (NBT) according to the method described by Parida and Jha (2010). The reaction mixture $(3 \mathrm{~mL})$ was composed of the enzyme extract $(20 \mu \mathrm{L})$, phosphate buffer $(50 \mathrm{mM}, \mathrm{pH} 7.8)$, methionine $(13 \mathrm{mM})$, NBT $(75 \mu \mathrm{M}), 0.1 \mathrm{mM}$ EDTA, and riboflavin $(2 \mu \mathrm{M})$. Tubes were illuminated at a light intensity of $4000 \mathrm{~lx}$ for about $15 \mathrm{~min}$. The absorbance of the mixture was read at $560 \mathrm{~nm}$. One unit of SOD was defined as the amount of enzyme that caused $50 \%$ inhibition of NBT reduction under light.

The CAT and POD activities were measured according to the method described by Chance and Maehly (1955). The CAT reaction mixture was composed of the enzyme extract $(50 \mu \mathrm{L})$, phosphate buffer $(50 \mathrm{mM}, \mathrm{pH} 7.0)$, and $\mathrm{H}_{2} \mathrm{O}_{2}(10.5 \mathrm{mM})$. The reaction was started by adding the supernatant. The evolution of the absorbance was followed every $30 \mathrm{~s}$ for $3 \mathrm{~min}$ at $240 \mathrm{~nm}$. One unit of enzyme activity was defined as the consumption of $1.0 \mu \mathrm{mol}$ of $\mathrm{H}_{2} \mathrm{O}_{2}$ per minute.

The POD activity was determined by the oxidation of guaiacol in the presence of $\mathrm{H}_{2} \mathrm{O}_{2}$. The reaction solution contained phosphate buffer $(50 \mathrm{mM}, \mathrm{pH} 7.0)$, guaiacal $(25 \mathrm{mM})$, and $\mathrm{H}_{2} \mathrm{O}_{2}(2.0 \mathrm{mM})$. The enzyme extract $(10 \mu \mathrm{L})$ was added to the reaction mixture $(3 \mathrm{~mL})$. The increase in absorbance at $470 \mathrm{~nm}$ was monitored to determine the POD activity. 
The APX activity was assayed as previously described by Nakano and Asada (1981). The reaction mixture was composed of the enzyme extract $(0.1 \mathrm{~mL})$, phosphate buffer ( $\mathrm{pH} 7.0,50 \mathrm{mM})$, ascorbate $(15 \mathrm{nM}), \mathrm{H}_{2} \mathrm{O}_{2}(0.3 \mathrm{mM})$. The decrease of the absorbance at $290 \mathrm{~nm}$ within $1 \mathrm{~min}$ was monitored after the addition of $\mathrm{H}_{2} \mathrm{O}_{2}$. One unit of APX was defined as an absorbance change of 0.1 per min at $25^{\circ} \mathrm{C}$.

\section{Estimation of the proline levels}

Proline levels in the spikelets were determined according to the method reported by Bates et al. (1973). A fresh spikelets sample $(0.1 \mathrm{~g})$ was homogenized in sulfosalicylic acid $(3 \% \mathrm{w} / \mathrm{v}$ in water, $5 \mathrm{~mL})$. After centrifugation at $12000 \mathrm{~g}$ for $15 \mathrm{~min}$ at $4{ }^{\circ} \mathrm{C}$, the supernatant (ca. $2 \mathrm{~mL}$ ) was added to a mixture containing acid ninhydrin reagent $(2 \mathrm{~mL})$ and glacial acetic acid $(2 \mathrm{~mL})$. The sample was boiled in a water bath at $100 \mathrm{n}$ absorbance change for $30 \mathrm{~min}$. After cooling, toluene $(5 \mathrm{~mL})$ was added to the supernatant. The absorbance of the resulting solution was read at $520 \mathrm{~nm}$ against a toluene blank. The level of proline was expressed in $\mu \mathrm{g} \mathrm{g}^{-1} \mathrm{FW}$.

\section{Statistical analysis}

The experiments were conducted with a minimum of three replicates and all the data were subjected to a one-way analysis of variance (ANOVA). The differences between individual mean values were determined by the Duncan's multiple-range test $(P<0.05)$ using the SAS software version 8.0 (SAS Institute, Cary, N.C., USA). In the case of the determination of the male sterility rate, the values were converted using $\theta=\sin \sqrt{p}$ arcsine.

\section{RESULTS}

\section{Morphological features of sterile foxtail millet induced by SQ-1}

The plants treated with SQ-1 did not develop spikelets in contrast to the non-treated plants as shown by the picture from Fig. 1. As expected, the sterilizing effects were more noticeable as the concentration of SQ-1 increased. Compared to the SQ-1 treated plants, the heads of the control foxtail millet plants were larger, the average spikelet length was longer, the grains appeared very full, and the overall color of the plant was of a shiny gold. In contrast, the SQ-1 treated plants presented smaller heads, a shorter average spikelet length, shrunken grains, and the overall spikelets exhibited a lighter color. Considering the stamens and pistils, the SQ-1 treated plants were characterized by smaller and twisted anthers compared to the normal ones of the control plants, although pistils of the treated plants showed a normal development (Fig. 2a, 2b). More importantly, the SQ-1 treated pollen were transparent after the staining test with $\mathrm{I}_{2}-\mathrm{KI}$ (Fig. 2c), which is in contrast with the deep blue colored pollens obtained from the untreated plants (Fig. 2d). These observations confirmed that the cytoplasm and nucleus were disintegrated in the sterile pollens. Moreover, the results confirmed the induction of male sterility under various treatments for the pollens of the untreated plant. The absence of starch in SQ-1 treated sterile pollens could support the research in starch depletion techniques. The presented results provide an important lead in unraveling the mode of action of SQ-1.

\section{Effect of the SQ-1 concentration on the male sterility and plant growth parameters}

We studied the influence of the SQ-1 concentration on the male sterility and plant growth parameters (plant height, panicle length, mean number of spikelets per ear, and the mean number of grains per spikelet). The data collected in 2015 and 2016 are summarized in Table 1. The highest male

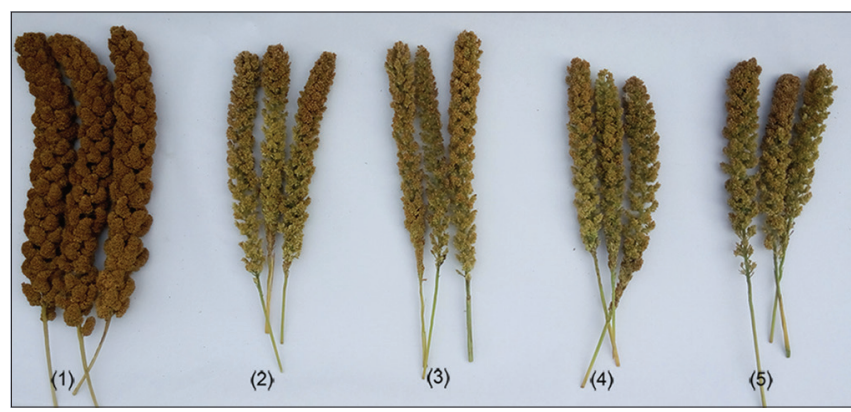

Fig 1. Excised florets from foxtail millet heads of the control (1) and SQ-1 treated plants with foliar applications (2, 3, 4, 5 corresponding to $3,4,5$, and $\left.6 \mathrm{~kg} \mathrm{ha}^{-1}\right)$.

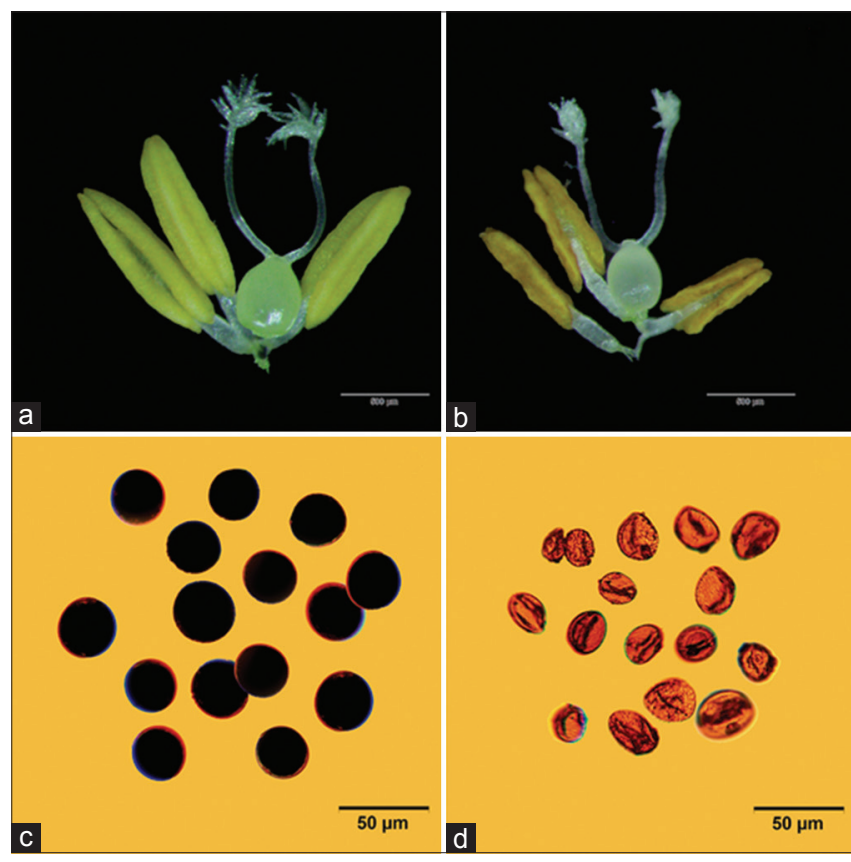

Fig 2. Morphological comparison of the control (left) and SQ-1 treated (right) foxtail millet plants. (a) and (b) are the stamens and pistils of the control and SQ-1 treated foxtail millet plants, respectively. (c) and (d) are the pollen grains obtained after the staining test with $2 \% \mathrm{I}_{2}-\mathrm{KI}$. 
sterility of $95.1 \%$ was obtained at the early protogyny stage in 2015 when using a concentration of SQ-1 of $6 \mathrm{~kg} \mathrm{ha}^{-1}$. However, there was no significant difference between the male sterility percentage obtained with a concentration of SQ-1 of $5 \mathrm{~kg} \mathrm{ha}^{-1}$ or of $6 \mathrm{~kg} \mathrm{ha}^{-1}(p<0.05)$. The value of the plant height gradually decreased when the concentration of SQ-1 increased. Overall, the application of SQ-1 showed no negative effects on the plant height until the concentration reached $6 \mathrm{~kg} \mathrm{ha}^{-1}$, at which concentration, the plant height decreased significantly $(P<0.05)$. The same tendency was observed for the other growth parameters: the panicle length, mean number of spikelets per ear, and the mean number of grain per spikelets. After the application of SQ-1, the panicle length decreased by $22.8 \%, 25.9 \%, 27.8 \%$, and $30.1 \%$ at the concentration of $3,4,5$, and $6 \mathrm{~kg} \mathrm{ha}^{-1}$, respectively. Concerning the mean number of spikelets per ear, we observed a reduction of $3.7 \%$ and $5.6 \%$ at the lower concentrations of SQ-1 (3 and $4 \mathrm{~kg} \mathrm{ha}^{-1}$, respectively), and at higher SQ-1 concentrations (5 and $6 \mathrm{~kg} \mathrm{ha}^{-1}$ ), the reduction reached $17.6 \%$ and $25.0 \%$, respectively. And more than $33.1 \%$ reduction of the mean number of grains per spikelets was observed when SQ-1 was applied.

The data collected in 2016 confirmed the effect of SQ-1 in inducing male sterility in foxtail millet. Indeed, the male sterility percentage in 2016 reached up to $95.7 \%$, and $95.9 \%$ when of the concentration of SQ-1 was 5 and $6 \mathrm{~kg} \mathrm{ha}^{-1}$, respectively. When a concentration of $6 \mathrm{~kg} \mathrm{ha}^{-1}$ of SQ-1 was applied, the plant height value was decreased by $24.4 \%$, and the one of the panicle length was decreased by $29.7 \%$. At the highest concentration of $6 \mathrm{~kg} \mathrm{ha}^{-1}$ of SQ-1, the mean number of spikelets per ear decreased by more than $27.5 \%$, whereas the mean number of grains per spikelets reduced by more than $48.8 \%$.

The spikelets were deformed after the application of SQ-1 at the early booting stage in 2015 and 2016. At the midbooting stage, all the plants did not form spikelets (data not shown in Table 1).
Effect of SO-1 on the concentrations of $\mathrm{H}_{2} \mathrm{O}_{2}$ and MDA produced by plants

It is well accepted that ROS can be produced by exogenous factors such as chemical agents. In order to reveal the relation between the abnormal concentrations of ROS and $\mathrm{CHA}$ induced male sterility in SQ-1 treated spikelets, the concentration of produced $\mathrm{H}_{2} \mathrm{O}_{2}$ was measured under various concentration applications of SQ-1 for 15 days (Fig. 3a). The results indicated that the lowest concentration of $\mathrm{H}_{2} \mathrm{O}_{2}$ of SQ-1-treated and control plants was observed at day 5, 13.7-15.8 and $11.76 \mathrm{~min}^{-1} \mathrm{~g}^{-1} \mathrm{FW}$, respectively. Up to day 10, the level of $\mathrm{H}_{2} \mathrm{O}_{2}$ observed for the treated spikelets compared to control rapidly increased by $24.4 \%$, $28.5 \%, 39.9 \%$, and $45.5 \%$ when a the concentration of SQ-1 was 3, 4, 5, and $6 \mathrm{~kg} \mathrm{ha}^{-1}$, respectively. From then on, a gradual decrease of the $\mathrm{H}_{2} \mathrm{O}_{2}$ level was observed at all SQ-1 concentrations. However, the concentration of $\mathrm{H}_{2} \mathrm{O}_{2}$ kept increasing after 10 days of experimental time in the control.

The effect of the concentration of SQ-1 on the MDA content is shown in Fig. 3b. The content of MDA detected in the treated plant spikelets significantly increased at all SQ-1 concentrations when compared to the one of the control plants. Indeed, the MDA content increased together with the concentration of SQ-1. The highest MDA content, which represented $104.7 \%$ more than that of the control plant, was recorded on day 15 at a SQ-1 concentration of $6 \mathrm{~kg} \mathrm{ha}^{-1}$ SQ-1. The lowest MDA content for the treated and control plants was observed at day 5 , from which on the synthesis of MDA rose continuously.

\section{Activities changes of the ROS scavenging enzymes}

The activities of the ROS scavenging Enzymes such as SOD, POD, CAT, and APX were analyzed in the SQ-1treated and the control plants (Fig. 5). The SOD activity increased continuously for the control plants as the treatment prolonged. In contrast, the enzymatic activity first decreased by day 10 and then increased by day 15 in the case of the SQ-1 treated plants (Fig. 5a). Overall,

\begin{tabular}{|c|c|c|c|c|c|c|c|c|c|c|}
\hline \multirow[t]{2}{*}{$\begin{array}{l}\text { Concentrations } \\
\left(\mathrm{kg} \mathrm{ha}^{-1}\right)\end{array}$} & \multicolumn{2}{|c|}{ Male sterility (\%) } & \multicolumn{2}{|c|}{ Plant height (cm) } & \multicolumn{2}{|c|}{ Panicle length $(\mathrm{cm})$} & \multicolumn{2}{|c|}{$\begin{array}{l}\text { Mean spikelet } \\
\text { number per ear }\end{array}$} & \multicolumn{2}{|c|}{$\begin{array}{l}\text { Mean grain } \\
\text { number per } \\
\text { spikelet }\end{array}$} \\
\hline & 2015 & 2016 & 2015 & 2016 & 2015 & 2016 & 2015 & 2016 & 2015 & 2016 \\
\hline 0 & 0.0 & 0.0 & $143.5 \pm 0.5 a$ & $144.3 \pm 1.6 a$ & $26.0 \pm 0.3 a$ & $26.5 \pm 0.4 a$ & $108 \pm 1 a$ & $111 \pm 3 a$ & $125 \pm 1 a$ & $126 \pm 1 a$ \\
\hline 3 & $86.4 \pm 0.6 \mathrm{c}$ & $86.8 \pm 0.3 c$ & $142.7 \pm 1.6 \mathrm{a}$ & $143.7 \pm 0.5 a$ & $20.1 \pm 0.4 b$ & $20.6 \pm 0.6 b$ & $104 \pm 2 a$ & $108 \pm 2 a$ & $85 \pm 2 b$ & $80 \pm 3 b$ \\
\hline 4 & $88.6 \pm 0.3 b$ & $88.7 \pm 0.8 b$ & $142.0 \pm 0.2 \mathrm{a}$ & $143.1 \pm 0.4 a$ & $19.3 \pm 0.3 b c$ & $19.8 \pm 0.8 b$ & $102 \pm 2 a$ & $107 \pm 4 a$ & $81 \pm 2 b c$ & $76 \pm 1 b c$ \\
\hline 5 & $94.8 \pm 0.5 a$ & $95.7 \pm 0.4 a$ & $140.8 \pm 0.1 \mathrm{a}$ & $141.0 \pm 0.7 a$ & $18.8 \pm 0.6 b c$ & $19.0 \pm 0.6 b$ & $89 \pm 3 b$ & $91 \pm 4 b$ & $77 \pm 3 c d$ & $70 \pm 2 \mathrm{~cd}$ \\
\hline 6 & $95.1 \pm 0.2 a$ & $95.9 \pm 0.8 a$ & $110.2 \pm 1.0 b$ & $111.8 \pm 1.5 b$ & $18.2 \pm 0.5 c$ & $18.6 \pm 0.6 b$ & $81 \pm 2 c$ & $81 \pm 5 b$ & $70 \pm 1 d$ & $64 \pm 1 d$ \\
\hline
\end{tabular}

The values are mean values $\pm S D(n=10)$. Different lower cased letters in one column indicate a significant difference with $P<0.05$ 


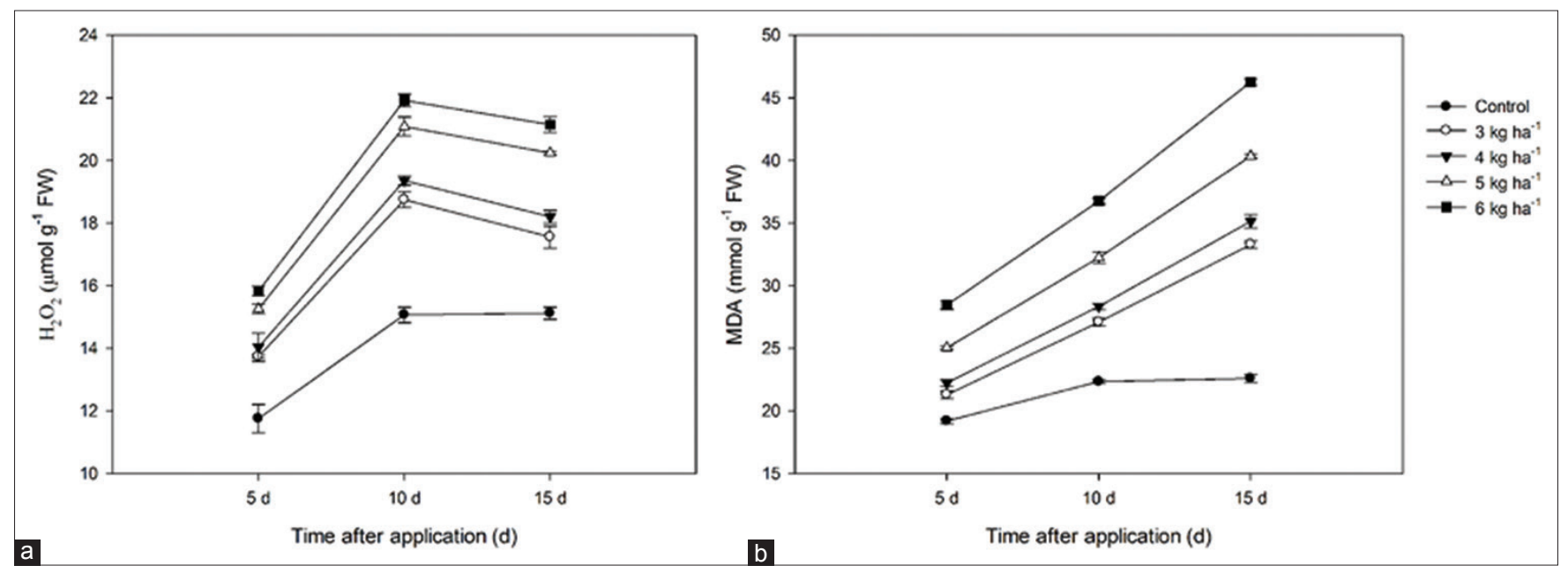

Fig 3. Effects of different concentrations of SQ-1 on the production of $\mathrm{H}_{2} \mathrm{O}_{2}$ and MDA in the spikelets of Henggu 13 at day 5, 10, and 15, respectively.

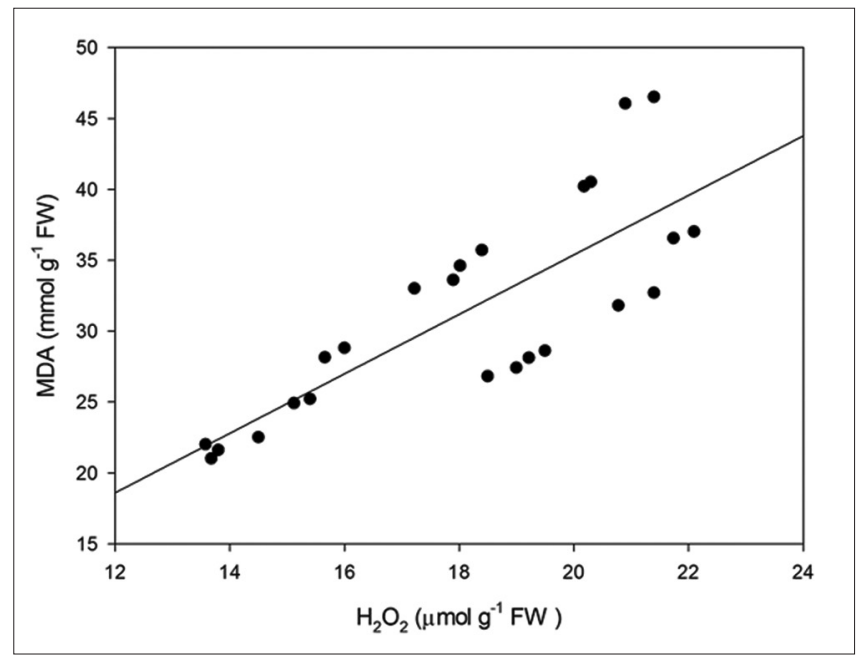

Fig 4. Correlation between the concentration of $\mathrm{H}_{2} \mathrm{O}_{2}$ and lipid peroxidation (MDA) content obtained by combining the data from all SQ-1 treated foxtail millet plants.

the SOD activity was always lower for the SQ-1-treated plants than for the control experiments. By day 10, the minimum enzymatic activity reduced by $39.2 \%$ at a SQ-1 concentration of $3 \mathrm{~kg} \mathrm{ha}^{-1}$, whereas the maximum decreased by $47.0 \%$ at a SQ-1 concentration of $6 \mathrm{~kg} \mathrm{ha}^{-1}$, when comparing the activities with the ones obtained for the control plants.

The application of SQ-1 induced the accumulation of POD inside the plant. In SQ-1 treated plants, the POD activity increased continuously during the application stage (Fig. 5b). At day 5, the POD activity of the SQ-1 treated plants increased by $75.1 \%$ at the concentration of $3 \mathrm{~kg} \mathrm{ha}^{-1}$, and was $1.6 \%$ higher than that of the control plants at the concentration of $6 \mathrm{~kg} \mathrm{ha}^{-1}$. By day 15, the POD activity increased by $48.1 \%-73.0 \%-73.0 \%$ with respect to the control plants.
The application of SQ-1 significantly influenced the CAT activity at all concentrations of SQ-1 (Fig. 5c). In general, the CAT activity lowered upon the application of SQ-1 $(P<0.05)$. The control plants exhibited first an increase in the CAT activity then a decrease as the experimental time increased. The treated plants exhibited the highest CAT activity of $12.2 \mathrm{~min}^{-1} \mathrm{~g}^{-1} \mathrm{FW}$ after 10 days of treatment; however, the activity decreased at first, and then increased. The CAT activity decreased together with the concentration of SQ-1. The lowest CAT activity was recorded after 10 days of treatment $\left(6 \mathrm{~kg} \mathrm{ha}^{-1}\right) \mathrm{SQ}-1$ and was 2.41 fold lower than the one of the control plants.

According to the ANOVA results, we found that the APX activity significantly changed upon treatment with SQ-1 $(P<0.05)$. As shown in Fig. 5d, the APX activity first increased, and then dropped with the course of the experiment for the SQ-1 treated and control plants. At day 10, the value of the high APX activity was 33.0, 29.0, 24.0, and $21.0 \mathrm{~min}^{-1} \mathrm{~g}^{-1} \mathrm{FW}$, at a SQ-1 concentration of 3, 4, 5, and $6 \mathrm{~kg} \mathrm{ha}^{-1}$. In short, the APX activity of the SQ-1 treated plants exhibited a reduction ranging from $16.2 \%$ to $51.4 \%$ lower than the ones of the control plants at all the stages of the treatment.

\section{Proline content variation}

The proline content was significantly affected in all SQ-1 treated plants. The amount of proline increased importantly in the control as the experimental time advanced. In contrast, a slow increase was observed for the SQ-1 treated plants (Fig. 6a). Furthermore, a much lower level of proline was noticed at all given concentrations of SQ-1 when compared to the ones of the control plants. At day 5 , the proline content of the treated plants declined by $35.7 \%, 45.3 \%, 56.1 \%$ and $59.4 \%$, when compared to the one of the control plants, at a SQ-1 concentration of 3, 4, 

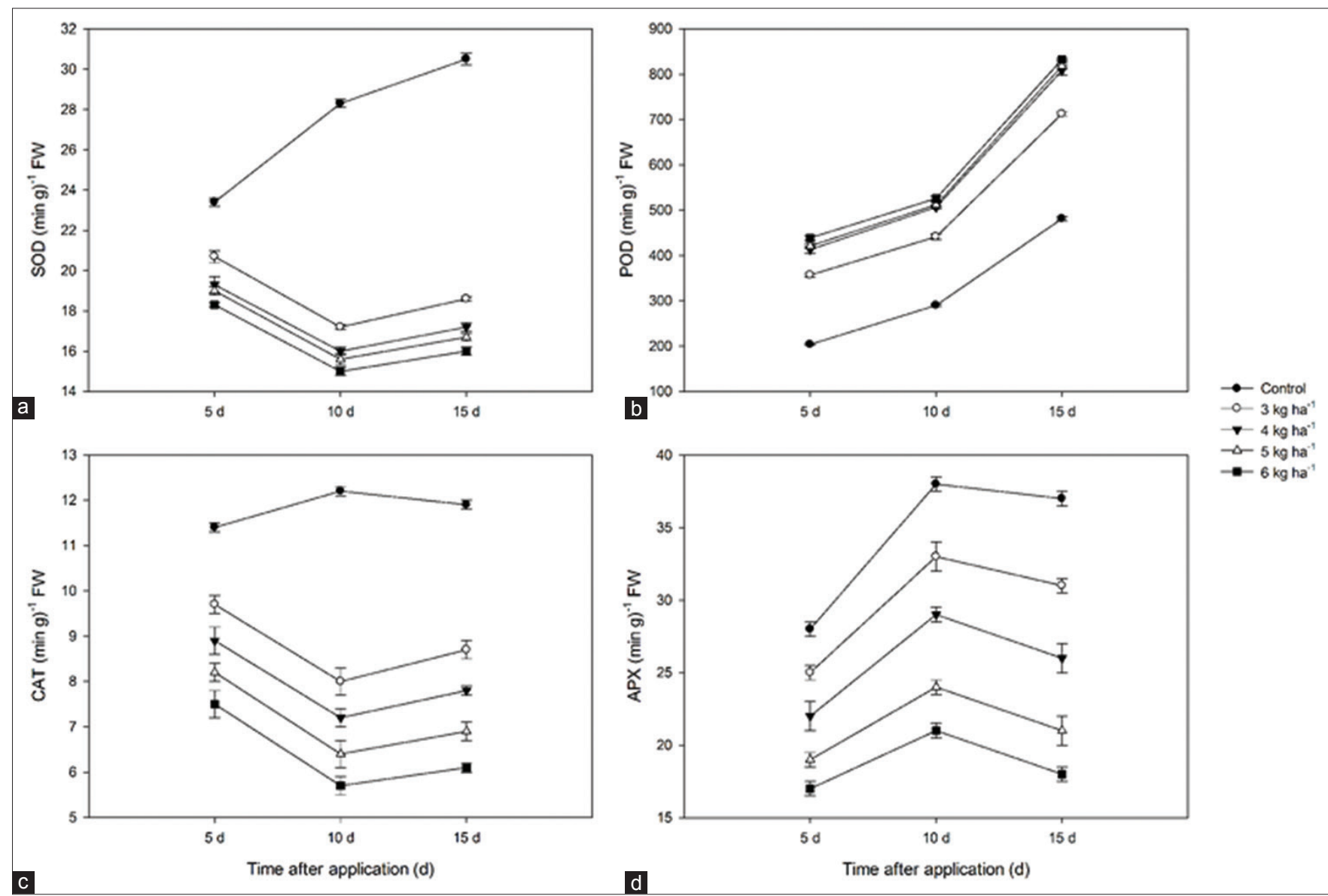

Fig 5. Effects of different concentrations of SQ-1 on various antioxidative enzymes in spikelets of Henggu 13 at day 5, 10, and 15. (a) Superoxide dismutase (SOD); (b) peroxidase (POD); (c) catalase (CAT), and (d) ascorbate peroxidase (APX).
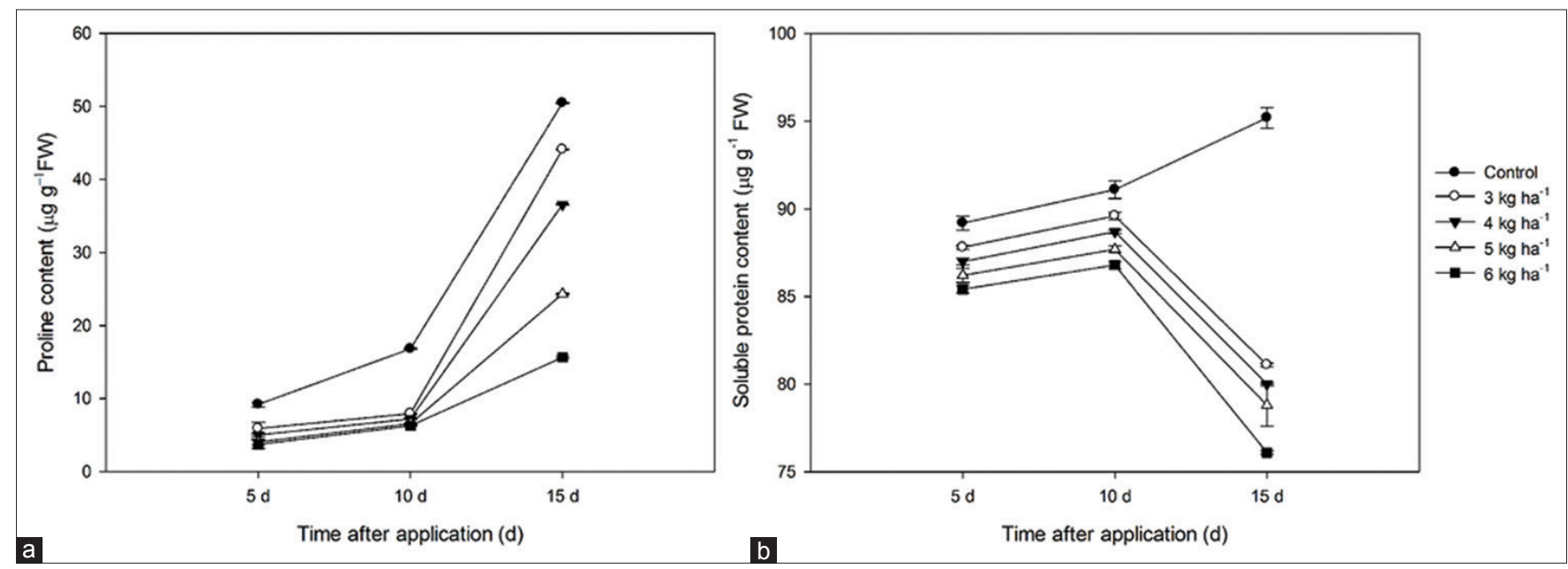

Fig 6. Effects of different concentrations of SQ-1 on the content of proline and the soluble protein in the spikelets of Henggu 13 at day 5,10 , and 15 , respectively.

5 , and $6 \mathrm{~kg} \mathrm{ha}^{-1}$. By day 21, the proline content decreased by 1.1 to 3.2 times the value of the control plants.

\section{Soluble protein content}

The determination of the content of soluble protein indicated that the initial protein content increased for both the treated and control plants. After 10 days, a continuous increase of the soluble protein content was observed for the control plant, in contrast to the decline observed for the SQ-1 treated spikelets. The most important reductions were of 1.04 fold, 1.05 fold, and 1.25 fold the control value at day 5, 10, and 20, respectively. In general, the soluble 
protein content of all SQ-1 treated plants was inherently significantly lower than the one of the control plants during the course of the experiment (Fig. 6b).

\section{DISCUSSION}

The results clearly demonstrated the potential of SQ-1 as a CHA for foxtail millet. The most effective dosage of SQ-1 was $5 \mathrm{~kg} \mathrm{ha}^{-1}$ and the most appropriate time was at the early protogyny. Indeed, at lower concentrations, less sterility was induced, and no significant increase was produced at higher concentration. At early booting, the application of SQ-1 led to no panicle exsertion, and abnormal ears were observed at the mid-booting stage. Our results corroborated the previous findings supporting that the optimal treatment time was at the male premeiotic archesporial development stage and terminates at the end of the premeiotic interphase (Bennett and Hughes, 1972; Hughes et al., 1974). In this study we have pin pointed the appropriate developmental stage at which SQ-1 was the most effective. Although cytological observations are possible, it was not practical to operate in the field. As a consequence, the external morphology of the plant corresponded to the inner growth and development stages. In our study, the leaf age was used to assess the developmental stage (Shanxi academy of agricultural science, 1987), which was more precise and practical.

Successful use of CHAs not only depends on the complete induction of male sterility, but also on the absence of negative side effects. In the current study, no apparent morphological abnormalities were observed while applying SQ-1. Moreover, SQ-1 had no side effect on female fertility except that the plant height decreased when the SQ-1 concentration increased, which may be advantageous for increasing the level of hybridization. Similar results had been reported for other CHAs on other crops, such as corn and soybean with Ethrel (Earley and Slife, 1969; Slife and Early, 1970).

Various environmental stresses can cause the overproduction of ROS, therefore the concentrations of ROS are used as stress indicators. It has been reported that SQ-1 could induce the overproduction of ROS during the anther abortion, which could be assimilated to a stress factor (Ba et al., 2013). In our study, after the application of SQ-1, the concentrations of ROS $\left(\mathrm{H}_{2} \mathrm{O}_{2}\right)$ increased in the plant spikelets, which was consistent with the previous stress studies (Kiani-Pouya, 2015). Furthermore, the overproduction of ROS increased together with the increase of SQ-1 concentration.

Excessive production of ROS causes oxidative injuries to lipid peroxidation as observed under different stress conditions for different plant species (Khoyerdi et al., 2016; Wang et al., 2015). The lipid peroxidation level was indirectly determined by the content of MDA in this study. We found that the application of SQ-1 triggered the MDA production earlier than in the case of the control plants (Fig. 3b). It has been reported that the low level of MDA could be associated with a better resistance to stress environment. The results of this study implied that the peroxidative reaction became more important in membrane lipids and that consequently the treated plants could be subjected to serious injury. Furthermore, the MDA level presented a significant positive correlation with the production of $\mathrm{H}_{2} \mathrm{O}_{2}(\mathrm{r}=0.641, p<0.001)$ (Fig. 4), implying that the generation of $\mathrm{H}_{2} \mathrm{O}_{2}$ could participate in the lipid peroxidation under SQ-1 treatment.

The SOD, CAT, POD, and APX are the major antioxidant enzymes associated with the scavenging of ROS. The major scavenger of superoxide $\left(\mathrm{O}_{2} \cdot-\right)$ is SOD by catalyzing the reaction of the superoxide anions into the $\mathrm{H}_{2} \mathrm{O}_{2}$ and $\mathrm{O}_{2}$ molecules, which can damage to nucleic acid and proteins. The enzymes POD and CAT (Gill and Tuteja, 2010) remove $\mathrm{H}_{2} \mathrm{O}_{2}$, while APX is involved in the ascorbateglutathione cycle, which also removes $\mathrm{H}_{2} \mathrm{O}_{2}$ but via a nonenzymatic pathway. It has been reported that SOD, CAT, POD, and APX increased in response to mild and moderate environmental stress (Ma et al.,2016; Shen et al., 2015; Liu et al., 2013). However, under severe stress, the functions of antioxidant enzymes tend to be impaired. In our study, we found that after application of SQ-1, the SOD and CAT activities decreased at earlier development stage of the plant, and then increased at a later stage. In contrast, the APX activity of treated plants first increased and then decreased in the plant spikelets when compared to the one of the control plant. Only the POD activity increased continuously for all treated plants. Overall, the activity of all the enzymes was always lower than that of the control plants, indicating that the ROS-scavenging system could not maintain the balance between the ROS overproduction and degradation. Consequently, the excessive accumulation of highly reactive and toxic ROS disrupted the normal metabolism of the plant, and led to the microspore male sterility.

\section{CONCLUSIONS}

The current study assessed the effect of SQ-1 on inducing male sterility in foxtail millet, and contributed to assessment of the relations between the metabolism of ROS and the SQ-1 induction of male sterility. The results have shown that in the sterile plants induced by SQ-1, the accumulation of $\mathrm{H}_{2} \mathrm{O}_{2}$ was much higher than the control. 
Meanwhile, the activities of SOD, CAT and APX were inhibited. Excessive ROS can not be removed timely by the antioxidative system, reducing the lipid peroxidation and oxidative damage. At the same time, the metabolism of the proline content and soluble protein was also dysfunctional, which affected the supply of energy and nutrient to the anthers. These results provide the basis theory for the study of the mechanism of physiological male sterility induced by SQ-1. However, the mechanisms related to CHA induced male sterility are complex, and the effects of other factors, such as total soluble sugars or specific phytohormones are still unknown. Further research is needed to obtain other physiology changes. Moreover, histological modifications are also needed to illuminate the mechanism of male sterility.

\section{ACKNOWLEDGMETS}

This research was supported by the Scientific and Technological Project in Shanxi Province, China (20150311016-2); and the Science and Technology Key Research Project in Shanxi Province, China (2015-TN-09); and the Graduate Innovative Research Project in Shanxi Province, China (2016BY068).

\section{Authors contributions}

The authors gratefully acknowledge the help of all authors of this paper. Xi'e Song and Yinyuan Wen were involved in literature collection, Jixiang Wang was involved in conducing experiments, Xiangyang Yuan and Shuqi Dong were involved in revising the language of this manuscript, Yuguo Wang was involved in designing the experiment, Pingyi Guo was the project director and guided the whole experiment.

\section{Abbreviations used}

$\mathrm{CHA}$, Chemical hybridization agent; ROS, reactive oxygen species; SOD, superoxide dismutase; POD, peroxidase; CAT, catalase; APX, ascrodate peroxidase; MDA, malondialdehyde.

\section{REFERENCES}

Apel, K. and H. Hirt. 2004. Reactive oxygen species: Metabolism, oxidative stress, and signal transduction. Annu. Rev. Plant Biol. 55: 373-399.

Asada, K. 1999. The water-water cycle in chloroplasts: Scavenging of active oxygens and dissipation of excess photons. Annu. Rev. Plant Biol. 50: 601-639.

Ba, Q., G. Zhang, J. Wang, N. Niu, S. Ma and J. Wang. 2014a. Gene expression and DNA methylation alterations in chemically induced male sterility anthers in wheat (Triticum aestivum L.). Acta Physiol. Plant. 36: 503-512.

Ba, Q., G. Zhang, J. Wang, H. Che, H. Liu, N. Niu and J. Wang. 2013. Relationship between metabolism of reactive oxygen species and chemically induced male sterility in wheat (Triticum aestivum L.). Can. J. Plant Sci. 93: 675-681.

Ba, Q., G. Zhang, H. Che, H. Liu, T. B. Ng, L. Zhang, J. Wang, Y. Sheng, N. Niu, S. Ma and J. Wang. 2014b. Aliphatic metabolism during another development interfered by chemical hybridizing agent in wheat. Crop Sci. 54: 1458-1467.

Bettinger, R. L., L. Barton and C. Morgan. 2010. The origins of food production in north China: A different kind of agricultural revolution. Evol. Anthropol. Issues News Rev. 19: 9-21.

Bates, L. S., R. P. Waldren and I. D. Teare. 1973. Rapid determination of free proline for water-stress studies. Plant Soil. 39: 205-207.

Bennett, M. D. and W. G. Hughes. 1972. Additional mitosis in wheat pollen induced by ethrel. Nature. 240: 566-568.

Bradford, M. M. 1976. Rapid and sensitive method for quantitation of microgram quantities of protein utilizing principle of proteindye binding. Anal. Biochem. 72: 248-254.

Brutnell, T. P., L. Wang, K. Swartwood, A. Goldschmidt, D. Jackson, X. Zhu, E. Kellogg and J. Eck. 2010. Setaria viridis: A model for C4 photosynthesis. Plant Cell. 22: 2537-2544.

Cakmak, I. and W. J. Horst. 1991. Effect of aluminium on lipid peroxidation, superoxide dismutase, catalase, and peroxidase activities in root tips of soybean (Glycine max). Physiol. Plant. 83: 463-468.

Chen, R. H., W. Liu, G. S. Zhang and J. Ye. 2010. Mitochondrial proteomic analysis of cytoplasmic male sterility line and its maintainer in wheat (Triticum aestivum L.). Agric. Sci. China. 9: 771-782.

Chance, B. and A. C. Maehly. 1955. Assay of catalases and peroxidases. Methods Enzymol. 2: 764-775.

Crawford, G. W. 2006. East Asian plant domestication. Archaeology of Asia, Blackwell, Malden, MA, pp. 77-95.

Doust, A. N., E. A. Kellogg, K. M. Devos and J. L. Bennetzen. 2009. Foxtail millet: A sequence-driven grass model system. Plant Physiol. 149: 137-141.

Earley, E. B. and F. W. Slife. 1969. Effect of ethrel on growth and yield of corn. Agron. J. 61: 821-823.

Fan, X. W., F. M. Li, L. Song, Y. C. Xiong, L. An, Y. Jia and X. W. Fang. 2009. Defense strategy of old and modern spring wheat varieties during soil drying. Physiol. Plant. 136: 310-323.

Ge, Y., X. He, J. Wang, B. Jiang, R. Ye and X. Lin. 2014. Physiological and biochemical responses of Phoebe bournei seedlings to water stress and recovery. Acta Physiol. Plant. 36: 1241-1250.

Gill, S. S. and N. Tuteja. 2010. Reactive oxygen species and antioxidant machinery in abiotic stress tolerance in crop plants. Plant Physiol. Biochem. 48: 909-930.

Girousse, C., R. Bournoville and J. L. Bonnemain. 1996. Water deficit-induced changes in concentrations in proline and some other amino acids in the phloem sap of alfalfa. Plant Physiol. 111: 109-113.

Hei, N., S. Hussein and M. Laing. 2016. Heterosis and combining ability analysis of slow rusting stem rust resistance and yield and related traits in bread wheat. Euphytica. 207: 501-514.

Ikeguchi, S., A. Hasegawa, T. Murai and K. Tsunewaki. 1999. Basic studies on hybrid wheat breeding using the 1BL-1RS translocation chromosome/Aegilops kotschyi cytoplasm system 1. Development of male sterile and maintainer lines with discovery of a new fertility-restorer. Euphytica. 109: 33-42.

Hughes, W. G., M. D. Bennett, J. J. Bodden and S. Galanopoulou. 1974. Effects of time of application of ethrel on male sterility and ear emergence in wheat Triticum aestivum. Ann. Appl. Biol. 76: 243-252.

Jia, G., X. Huang, H. Zhi, Y. Zhao, Q. Zhao, W. Li, Y. Chai, L. Yang, 
K. Liu, H. Lu, C. Zhu, Y. Lu, C. Zhou, D. Fan, Q. Weng, Y. Guo, T. Huang, L. Zhang, T. Lu, Q. Feng, H. Hao, H. Liu, P. Lu, N. Zhang and Y. Li. 2013. A haplotype map of genomic variations and genome-wide association studies of agronomic traits in foxtail millet (Setaria italica). Nat. Genet. 45: 957-961.

Kalloo, G., M. Rai, M. Singh and S. Kumar. 2006. Heterosis in Crop Plants, Researchco Book Centre, New Delhi.

Khoyerdi, F. F., M. H. Shamshiri and A. Estaji. 2016. Changes in some physiological and osmotic parameters of several pistachio genotypes under drought stress. Sci. Hortic. 198: 44-51.

Kiani-Pouya, A. 2015. Changes in activities of antioxidant enzymes and photosynthetic attributes in triticale $(\times$ Triticosecale Wittmack) genotypes in response to long-term salt stress at two distinct growth stages. Acta Physiol. Plant. 37: 1-11.

Krasensky, J. and C. Jonak. 2012. Drought, salt, and temperature stress-induced metabolic rearrangements and regulatory networks. J. Exp. Bot. 63: 1593-1608.

Lata, C., S. Gupta and M. Prasad. 2013. Foxtail millet: A model crop for genetic and genomic studies in bioenergy grasses. Crit. Rev. Biotechnol. 33: 328-343.

Li, P. and T. P. Brutnell. 2011. Setaria viridis and Setaria italica, model genetic systems for the Panicoid grasses. J. Exp. Bot. DOI: 10.1093/jxb/err096.

Liu, C., Y. Liu, K. Guo, D. Fan, G. Li, Y. Zheng, L. Yu and R. Yang. 2011. Effect of drought on pigments, osmotic adjustment and antioxidant enzymes in six woody plant species in karst habitats of southwestern China. Environ. Exp. Bot. 71: 174-183.

Liu, D., L. Wu, M. S. Naeem, H. Liu, X. Deng, L. Xu, F. Zhang and W. Zhou. 2013. 5-Aminolevulinic acid enhances photosynthetic gas exchange, chlorophyll fluorescence and antioxidant system in oilseed rape under drought stress. Acta Physiol. Plant. 35: 2747-2759.

Lu, H., J. Zhang, K. Liu, N. Wu, Y. Li, K. Zhou, M. Ye, T. Zhang, H. Zhang, X. Yang, L. Shen, D. Xu and Q. Li. 2009. Earliest domestication of common millet (Panicum miliaceum) in East Asia extended to 10,000 years ago. Proc. Natl. Acad. Sci. 106: 7367-7372.

Ma, J., C. Lv, M. Xu, G. Chen, C. Lv and Z. Gao. 2016. Photosynthesis performance, antioxidant enzymes, and ultrastructural analyses of rice seedlings under chromium stress. Environ. Sci. Pollut. Res. Int. 23: 1768-1778.

Matz, S. A. 1991. Chemistry and Technology of Cereals as Food and Feed, Springer Science and Business Media, New York, USA.

Nakano, Y. and K. Asada. 1981. Hydrogen peroxide is scavenged by ascorbate-specific peroxidase in spinach chloroplasts. Plant Cell Physiol. 22: 867-880.

Parida, A. K. and B. Jha. 2010. Antioxidative defense potential to salinity in the euhalophyte Salicornia brachiata. J. Plant Growth Regul. 29: 137-148.

Patterson, B. D., E. A. MacRae and I. B. Ferguson. 1984. Estimation of hydrogen peroxide in plant extracts using titanium (IV). Anal.
Biochem. 139: 487-492.

Saleh, A. S. M., Q. Zhang, J. Chen and Q. Shen. 2013. Millet grains: Nutritional quality, processing, and potential health benefits. Compr. Rev. Food Sci. Food Saf. 12(3): 281-295.

Shanxi Academy of Agricultural Science. 1987. Foxtail Millet Cultivation Science in China, Chinese Agricultural Scientific Academy, China.

Shen, X., Z. Dong and Y. Chen. 2015. Drought and UV-B radiation effect on photosynthesis and antioxidant parameters in soybean and maize. Acta Physiol. Plant. 37: 1-8.

Singh, S. P., R. Srivastava and J. Kumar. 2015. Male sterility system in wheat and opportunities for by brid wheat development. Acta Physiol. Plant. 37: 1713.

Slife, F. W. and E. B. Early. 1970. Effect of etherel on growth and yield of soybeans. Agron. J. 62: 434-435.

Smirnoff, N. 1993. The role of active oxygen in the response of plants to water deficit and desiccation. New Phytol. 125: 27-58.

Sun, W., M. V. Montagu and N. Verbruggen. 2002. Small heat shock proteins and stress tolerance in plants. BBA Gene Struct. Exp. 1577: $1-9$

Teisseire, H. and V. Guy. 2000. Copper-induced changes in antioxidant enzymes activities in fronds of duckweed (Lemna minor). Plant Sci. 153: 65-72.

Upadhyaya, H. D., C. R. Ravishankar, Y. Narasimhudu, N. D. R. Sarma, S. K. Singh, S. K. Varshney, V. G. Reddy, S. Singh, H. K. Parzies, S. L. Dwivedi, H. L. Nadaf, K. L. Sahrawat and C. L. L. Gowda. 2011. Identification of trait-specific germplasm and developing a mini core collection for efficient use of foxtail millet genetic resources in crop improvement. Field Crop. Res. 124: 459-467.

Wang, Y., G. Yu, K. Li, M. Wu, J. Ma, J. Xu and G. Chen. 2015. Responses of photosynthetic properties and antioxidant enzymes in high-yield rice flag leaves to supplemental UV-B radiation during senescence stage. Environ. Sci. Pollut. R. 22: 4695-4705.

Yang, X., Z. Wan, L. Perry, H. Lu, Q. Wang, C. Zhao, J. Li, F. Xie, J. Yu, T. Cui, T. Wang, M. Li and Q. Ge. 2012. Early millet use in northern China. Proc. Natl. Acad. Sci. 109: 3726-3730.

Zhu, Q., G. Zhang, X. Zhao, X. Zhang and S. Yang. 2012. Determination of clofencet in wheat using ultrasound-assisted extraction by high performance liquid chromatography. Chin. J. Anal. Chem. 40: 462-465.

Zhu, Q., Q. Sang, C. P. Wang, G. Zhang, Z. Chen, X. Zhao, S. Ma, J. Wang and N. Niu. 2013. Determination of clofencet in wheat grain by high performance liquid chromatography. Chin. J. Anal. Chem. 41: 565-569.

Zohary, D., M. Hopf and E. Weiss. 2012. Domestication of Plants in the Old World: The Origin and Spread of Domesticated Plants in Southwest Asia, Europe, and the Mediterranean Basin, Oxford University Press on Demand, New York. 